\title{
Correlation between the storability and fruit quality of fresh goji berries
}

\author{
Ting HUANG ${ }^{1}$ (D), Ken QIN ${ }^{1 \star}$, Yamei YAN ${ }^{1}$, Xinru HE${ }^{1}$, Guoli DAI ${ }^{1}$, Bo ZHANG ${ }^{1}$
}

\begin{abstract}
Poor storability is the largest problem thwarting the marketization of fresh goji berries (Lycium barbarum L.). In this study, the storability of fresh fruits from 31 varieties of goji berry was evaluated by their decay index and rate of decay to choose 13 varieties of fresh fruit with excellent, medium and poor storability. Correlation and partial least squares regression analyses were adopted to explore the correlations between storability and 16 physical and chemical indicators from summer and autumn fruits. The storability calculated by the decay rate is significantly positively correlated with the content of flavonoids in the summer fruits, while the storability calculated by the decay index is significantly negatively correlated with the color difference $\mathrm{b}^{\star}$ and total acids in the summer fruits $(P<0.05)$. Similarly, the storability calculated by the decay rate is significantly positively correlated with the content of flavonoids, chewiness and elasticity of the autumn fruits $(P<0.05)$. The storability calculated by the decay index is significantly positively correlated with the content of flavonoids and the chewiness of autumn fruits $(P<0.05)$. The content of flavonoids in the fresh goji berry revealed a significantly positive correlation with the storability.
\end{abstract}

Keywords: goji berry; fresh fruit; storability; fruit quality; flavonoids.

Practical Application: The research results will point out the direction for the breeding of Lycium barbarum fresh fruit varieties and the development of preservation technology.

\section{Introduction}

Goji berry (Lycium barbarum L.) belongs to the Solanaceae family. Its fruit is a Chinese herb with both medicinal and food functions. Its applications in clearing the liver and improving eyesight, lowering blood glucose and enhancing beauty have a history of more than 500 years (Muatasim et al., 2018; Jin et al., 2013; Zhou et al., 2018). Goji berry is usually consumed in the form of dry products. Research shows that the extract of Goji berry has many functions. Extracts have been shown to protect against neurodegeneration in the retina of a rat $\mathrm{OH}$ model (Chan et al., 2007). The flavonoid fraction in Goji berry was the most effective at scavenging DPPH and $\mathrm{ABTS}^{+}$free radicals, chelating metal ions and reducing power, while the zeaxanthin fraction and polysaccharides showed the most pronounced effect in scavenging hydroxy free radicals and superoxide anions, respectively (Wang et al., 2010). A larger amount of research focuses on the efficacy of Goji berry polysaccharide and its complex. The Goji berry polysaccharides can compensate for the decline in total antioxidant capacity, immune function and the activities of antioxidant enzymes, and thereby reduce the risks of lipid peroxidation accelerated by age-induced free radicals (Li et al., 2007). The polysaccharide-protein complex from goji berries can activate T cells, and it also has a hypoglycemic effect (Zou et al., 2010; Potterat, 2010; Chen et al., 2008). However, the drying process can cause the loss of nutrients. The type of berries available in the fresh fruit markets in Central and Northern Europe is increasing each year (Jatoi et al., 2017; Schiassi et al., 2020), and the nutritional value and sensory acceptance of berries are highly valued (Costa et al., 2019; Schiassi et al., 2020). Goji berries with a high nutritional value are considered to be the latest "super foods" or "super fruits" due to their unique taste and functions (Kafkaletou et al., 2017). Fruit coproducts, made of peels, seeds and pulp, discarded during the industrial processing, contain lots of health beneficial compounds (Silva et al., 2020), therefore, the significant differences of nutritional components and storability among varieties are particularly important in the selective drying, juicing and extraction of effective ingredients of berries (Jasmi et al., 2020; Manochai et al., 2018).

The goji berries fruits have a double "S" curve as they develop, indicating that the contents of soluble total sugar, reducing sugar, total acids, vitamin C, soluble proteins, polysaccharides, carotenoids and other nutrients can reveal a sharp increase up to a peak level at a certain developmental period (Zhao et al., 2015). Therefore, poor storability is the greatest problem thwarting the marketization of fresh goji berries. The fresh goji berries can turn brown during storage at room temperature for 2-3 days. Although the flesh of brown goji berries is still edible, the commercial value of the fruits has already been compromised (Jatoi et al., 2017).

Currently, most studies on the preservation of goji berries are focused on the change in storage conditions or the treatments with exogenous substances. The major methods for the preservation of goji berries include physical methods, such as low-temperature refrigeration, modified atmosphere refrigeration, heat treatment, radiation preservation, and pressure-reducing preservation (Jatoi et al., 2018; Ozturk et al., 2019; Ban et al., 2015); chemical methods, such as plant growth regulators and chemical preservatives (Bulens et al., 2012; Barberis et al., 2019); and biological methods, such as biological extracts from natural substances (Li et al., 2018; Zhang et al., 2018). However, these 
methods are still limited to the research stage and have not been widely used in practical production. Therefore, it is still a substantial problem to explore effective and low-cost processing for the technology to keep goji berries fresh on a large-scale (Shi et al., 2016).

During studies on the storage of fruits and vegetables, the difference in the storability between varieties has attracted more attention, with the exception of traditional preservation methods (Obianom et al., 2019). Studies have shown a large difference in the major and minor metabolites from different varieties of red cherries after harvesting, in the contents of components in different varieties of potatoes during storage, and in the storability of different varieties of grapes (Kiprovski et al., 2018; Gancarz, 2018; Cefola et al., 2018). Typically, the varieties that mature late store better than the varieties with medium or early maturity. The period during storage in which different varieties of litchi can be kept fresh is significantly different (Su et al., 2019). Japanese scientists have also discovered a type of "stone peach," with a high degree of fruit hardness, brittle flesh, the ability to hang on the tree for a long time and to resist softening after harvest (Hayama et al., 2006). Other Solanaceous species, such as peppers and tomatoes, with high storability have also been selected (Huang et al., 2018). The investigation of the storage time of fresh fruits from 35 varieties of goji berries during the preliminary study of this project indicated that the storage time of fresh fruits from different varieties that stored the best was more than eight days during storage at $6{ }^{\circ} \mathrm{C}$ compared with that of the varieties that stored poorly. Therefore, studying the storability of fresh fruits from the perspective of varieties can not only reduce cost and is suitable for practical production but can also result in a breakthrough in storage time, which will become a new way to explore the storability of fresh goji berries fruits. In this study, fresh fruits from 31 varieties of goji berries were used as materials to study the correlation between the storability and fruit quality of fresh fruits, which will provide a theoretical basis for developing fresh goji berries as a marketable fruit.

\section{Materials and methods}

\subsection{Raw materials of goji berries}

The varieties of goji berries tested (Table 1) were selected from the Chinese national goji berries resources (latitude $38^{\circ} 38^{\prime} 50^{\prime \prime}$, longitude $\left.106^{\circ} 9^{\prime} 13^{\prime \prime}\right)$. The summer fruits were picked on July 10,2018 , and the autumn fruits were picked on September 26, 2018. The storability of goji berries was determined within $2 \mathrm{~h}$ after harvesting. The appearance quality index was evaluated within $12 \mathrm{~h}$ after harvesting, and the intrinsic quality index was determined within $48 \mathrm{~h}$.

\subsection{Analytical methods for storability}

A total of 50 mature and pest-free fresh goji berries fruits of each variety were harvested and then placed in a box to keep them fresh. The box had a bottom dimension of $10 \mathrm{~cm} \times 20 \mathrm{~cm}$, with the fruit evenly distributed at the bottom surface without squeezing each other. Each variety was tested in triplicate. The boxes to keep the fruit fresh were placed in a $6{ }^{\circ} \mathrm{C}$ cabinet with no additional air flow. The decay rate and decay index were determined every 24 hours (Equations 1 and 2).

Decay rate $(\%)=($ the number of decay fruits $/ 50) \times 100 \%$

Storability $=1-$ decay rate

Based on the degree of the surface decay of fresh fruits, they were divided into six grades (Figure 1). The decay index $(\%)=$ (decay degree $x$ the number of decay fruits at this degree) / (the highest degree $\times$ total fruit number) $\times 100 \%$.

- Grade 0: Fresh fruit surface is intact;

- Grade 1: A little mildew or decay occurred on the surface of fresh fruits, but it did not cover more than $1 / 5$ of the surface area of the fruits.

- Grade 2: Some of the fresh fruits were mildewed or spoiled, ranging from $1 / 5$ to $2 / 5$.

- Grade 3: Some of the fresh fruits were mildewed or decayed, ranging from $2 / 5$ to $3 / 5$.

- Grade 4: Some of the fresh fruits were mildewed or decayed, ranging from $3 / 5$ of the surface area to $4 / 5$ of the surface area.

- Grade 5: There are numerous rotten fruit or surfaces that have rotted - between $4 / 5$ of the fruit surface area and the whole fruit surface area.

\subsection{Measurement of fruit physical indicators}

Fruit handle-pulling strength: Ten fresh fruits were selected by the quadruple method, and the fruit handle-pulling strength of each fruit was determined using a force meter (Aidelberg 2016 HP series push-pull force meter, Shanghai, China), and the average fruit handle-pulling strength was calculated. The 100-grain weight parameter: One hundred fresh fruits were selected by the quadruple method, and the 100-grain weight was determined using an electronic balance (Beijing, China) with three replicates to calculate the average 100-grain weight. Color difference: Ten fresh fruits were screened by the quadruple method, and the color values of each fresh fruit at two symmetric points were measured by a color difference meter (CM-5, Osaka, Japan), and the average value was calculated. Hardness: Ten fresh fruits were screened using the quadruple method. The hardness was measured one by one using a texture analyzer (US FTCTMS-PRO) with the installment of a $10 \mathrm{~N}$ force sensor and needle probe, as well as a puncture program. The setting for the maximum force of the parameter was $8 \mathrm{~N}$ (force sensing of $80 \%$ ); the range was $10 \mathrm{~N}$; the triggering force was $0.05 \mathrm{~N}$; the measuring speed was $30 \mathrm{~mm} \cdot \mathrm{min}^{-1}$; the puncture distance was $7 \mathrm{~mm}$; the returning speed was $60 \mathrm{~mm} \cdot \mathrm{min}^{-1}$, and the returning distance was $15 \mathrm{~mm}$. The average hardness was calculated. Adhesiveness, cohesiveness, chewiness and elasticity: Ten fresh fruits of uniform size were selected from each variety, and the adhesiveness, cohesiveness, chewiness and elasticity were measured singly using a texture analyzer. 
Table 1. The storability of 31 varieties of goji berries with their corresponding rank list.

\begin{tabular}{|c|c|c|c|c|c|c|c|c|}
\hline \multirow{2}{*}{ Varieties } & \multicolumn{6}{|c|}{ Decay rates $(\%)$} & \multirow{2}{*}{$\begin{array}{c}\text { Storability } \\
\text { rank }\end{array}$} & \multirow{2}{*}{$\begin{array}{c}\text { Selection of } \\
\text { varieties }\end{array}$} \\
\hline & $48 \mathrm{~h}$ & $72 \mathrm{~h}$ & $96 \mathrm{~h}$ & $120 \mathrm{~h}$ & $144 \mathrm{~h}$ & $168 \mathrm{~h}$ & & \\
\hline $14-87$ & $2 \pm 0$ & $2 \pm 1.00$ & $2 \pm 1.00$ & $4 \pm 1.73$ & $4 \pm 1.73$ & $14 \pm 2.64$ & 1 & \\
\hline $14-20$ & 0 & 0 & 0 & 0 & $8 \pm 2.44$ & $14 \pm 3.46$ & 2 & $\sqrt{ }$ \\
\hline $16-14-5-4$ & 0 & $2 \pm 0$ & $2 \pm 1.00$ & $4 \pm 1.41$ & $8 \pm 1.73$ & $26 \pm 2.00$ & 3 & $\sqrt{ }$ \\
\hline 14-401 & $2 \pm 0$ & $2 \pm 0$ & $4 \pm 1.58$ & $4 \pm 1.41$ & $10 \pm 1.73$ & $26 \pm 2.00$ & 4 & $\sqrt{ }$ \\
\hline $16-1-4-3$ & $6 \pm 0$ & $6 \pm 1.58$ & $6 \pm 1$ & $8 \pm 1.73$ & $10 \pm 1.73$ & $18 \pm 2.00$ & 5 & $\sqrt{ }$ \\
\hline 09-02 & 0 & $4 \pm 1.00$ & $4 \pm 1.00$ & $6 \pm 1.58$ & $14 \pm 1.73$ & $26 \pm 2.64$ & 6 & \\
\hline $14-2-3-20$ & 0 & 0 & $2 \pm 1$ & $4 \pm 1.73$ & $16 \pm 2.00$ & $30 \pm 2.64$ & 7 & $\sqrt{ }$ \\
\hline 14-104 & 0 & $2 \pm 0$ & $2 \pm 1.41$ & $6 \pm 1.00$ & $16 \pm 1.58$ & $32 \pm 2.83$ & 8 & \\
\hline $16-1-3-5$ & 0 & $2 \pm 0$ & $2 \pm 1.00$ & $4 \pm \pm 1.33$ & $16 \pm 1.66$ & $28 \pm 2.23$ & 9 & $\sqrt{ }$ \\
\hline $16-16-7-6$ & 0 & $2 \pm 0$ & $2 \pm 0$ & $6 \pm 1.58$ & $16 \pm 2.00$ & $30 \pm 2.00$ & 10 & \\
\hline Ningqi No.1 & 0 & 0 & $4 \pm 1.41$ & $6 \pm 2.23$ & $18 \pm 1.73$ & $28 \pm 2.64$ & 11 & $\sqrt{ }$ \\
\hline F1-14-1 & $4 \pm 0$ & $6 \pm 1.58$ & $6 \pm 1$ & $8 \pm 1.41$ & $20 \pm 1.58$ & $36 \pm 2.44$ & 12 & \\
\hline Jingqi No.4 & 0 & 0 & 0 & $4 \pm 1.58$ & $22 \pm 2.64$ & & 13 & \\
\hline Ningqi No.5 & $8 \pm 1.41$ & $10 \pm 1.73$ & $10 \pm 1.64$ & $16 \pm 2.00$ & $22 \pm 2.83$ & & 14 & $\sqrt{ }$ \\
\hline 14-402 & 0 & $2 \pm 1.00$ & $4 \pm 1.58$ & $6 \pm 1.58$ & $24 \pm 2.44$ & & 15 & $\sqrt{ }$ \\
\hline 14-404 & $6 \pm 1.58$ & $6 \pm 1.58$ & $6 \pm 1.41$ & $8 \pm 1.00$ & $24 \pm 2.23$ & & 16 & \\
\hline $14-4-4-13$ & $6 \pm 1.73$ & $10 \pm 2.23$ & $10 \pm 1.73$ & $14 \pm 2.00$ & $24 \pm 2.83$ & & 17 & \\
\hline $14-Z-222$ & 0 & $4 \pm 1.00$ & $8 \pm 1.58$ & $10 \pm 1.73$ & $26 \pm 2.23$ & & 18 & \\
\hline Z46 & $2 \pm 0$ & $2 \pm 0$ & $2 \pm 1.00$ & $8 \pm 1.73$ & $26 \pm 2.44$ & & 19 & \\
\hline $13-11$ & 0 & $2 \pm 0$ & $10 \pm 1.73$ & $16 \pm 1.58$ & $28 \pm 2.23$ & & 20 & \\
\hline $14-16$ & 0 & $2 \pm 0$ & $2 \pm 1.58$ & $6 \pm 2.00$ & $28 \pm 1.73$ & & 21 & $\sqrt{ }$ \\
\hline $16-23-8-10$ & 0 & $6 \pm 1.58$ & $8 \pm 2.23$ & $10 \pm 1.73$ & $28 \pm 2.83$ & & 22 & \\
\hline 404 & 0 & $2 \pm 0$ & $2 \pm 1.00$ & $6 \pm 1.41$ & $28 \pm 1.73$ & & 23 & \\
\hline Z44 & 0 & 0 & $2 \pm 0$ & $8 \pm 1.73$ & $28 \pm 3.46$ & & 24 & $\sqrt{ }$ \\
\hline 405 & 0 & $2 \pm 0$ & $2 \pm 1.00$ & $10 \pm 2.23$ & $30 \pm 2.64$ & & 25 & \\
\hline 13-19 & $16 \pm 1.58$ & $20 \pm 1.41$ & $28 \pm 2.23$ & $28 \pm 2.64$ & $32 \pm 2.64$ & & 26 & \\
\hline $16-16-9-2$ & $2 \pm 0$ & $6 \pm 2.00$ & $6 \pm 2.23$ & $12 \pm 1.41$ & $32 \pm 2.83$ & & 27 & $\sqrt{ }$ \\
\hline Z168 & $2 \pm 0$ & $2 \pm 1.00$ & $6 \pm 1.73$ & $18 \pm 2.64$ & $32 \pm 1.64$ & & 28 & $\sqrt{ }$ \\
\hline F1-14-5 & 0 & $4 \pm 1.00$ & $6 \pm 1.00$ & $10 \pm 2.23$ & $34 \pm 1.73$ & & 29 & \\
\hline $16-23-7-8$ & 0 & $2 \pm 1.00$ & $8 \pm 1.73$ & $32 \pm 2.64$ & $40 \pm 3.46$ & & 30 & \\
\hline Ningqi No.7 & $32 \pm 2.64$ & $40 \pm 2.23$ & $48 \pm 2.83$ & $52 \pm 3.46$ & $52 \pm 3.46$ & & 31 & \\
\hline
\end{tabular}
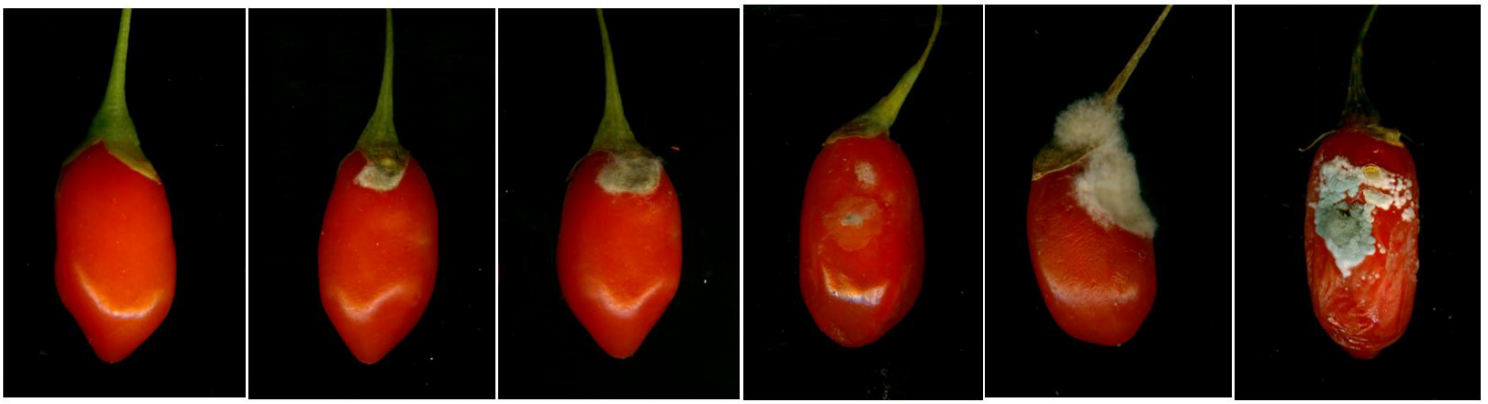

Grade0

Grade1

Grade2

Grade3

Grade4

Grade5

Figure 1. Classification of the Decay Degree of Fresh Fruits of Lycium barbarum L.

\subsection{Determination of fruit components}

The contents of the goji berries polysaccharides, total sugar, betaine, flavonoids, total acids and vitamin $\mathrm{C}$ were analyzed by the Ningxia Agricultural Products Quality Monitoring Center of China.
Determination of soluble solids: Ten fresh fruits were screened by the quadruple method; the surface was rinsed with distilled water, and the fresh fruits were ground and evenly mixed. The homogenous mixture from the fresh fruits was 
dripped on the prism surface of a hand-held sugar meter (Japan ATAGO Aiqi) with zero adjustment to determine the content of soluble solids. The average value was calculated using three measurements.

\subsection{Statistical analysis}

All the tests were repeated three times in each group when no specific instructions were provided. All the data were analyzed with a one-way ANOVA and Pearson correlation analysis (two-tailed test) using SPSS 23.0 (IBM, SPSS, Armonk, NY, USA). The data were subjected to regression analysis using SIMCA-P 11.5 (Umetrics,Malmo, Sweden) to establish a histogram of regression coefficients and importance indicators. The difference was considered significant at $P<0.05$, and every significant difference was evaluated at $P<0.01$.

\section{Results}

\subsection{Initial screening of storability}

The fresh fruits from some varieties began to decay $96 \mathrm{~h}$ after harvesting, and the decay rates of some varieties after harvesting for $168 \mathrm{~h}$ reached more than $50 \%$, thereby losing their commercial value. The decay rates of the fresh fruits at $144 \mathrm{~h}$ after harvest were used to calculate the storability of 31 varieties of goji berries with a corresponding rank list (Table 1). The results show a significant difference in storability for the fresh fruits from different varieties. The varieties with higher rank, such as "14-87" and "14-20," required more than 8 days to reach decay rates similar to the varieties with a lower rank, such as "16-23-7-8" and "Ningqi No. 7." Therefore, the increase in the decay rate of fresh goji berries fruits was in the range of 48-192 $\mathrm{h}$ after harvesting.

According to the classification of 31 varieties, the fresh fruits from 13 varieties were screened to represent excellent, medium and poor storability to explore the correlation between storability and fruit quality (Table 1).

\subsection{Correlation analysis}

The correlation analysis between the storability of fresh fruits from 13 varieties at different harvesting stages (summer and autumn fruits) and 16 factors (100-grain weight, maximum single fruit weight, fruit hardness, fruit handle-pulling strength, soluble solids, color difference $\mathrm{L}^{*}$, color difference $\mathrm{a}^{*}$, color difference $b^{*}$, cohesiveness, elasticity, adhesiveness, chewiness, total acids, vitamin C, betaine, and flavonoids) was conducted, as shown in Tables 2 and 3.

The decay rate reflects the breakage rate of fresh fruits. Regardless of the size of the decay area, damage will increase the decay rate. The decay index is calculated based on the size of decay area; thus, it reflects the development of the speed of decay after the fresh fruits were damaged. The storability of the summer fruits calculated by the decay rate of goji berries revealed a significantly positive correlation with the content of flavonoids. In contrast, the storability calculated by the decay index exhibited a significantly negative correlation with color difference $b^{*}$ and the content of total acids. Therefore, it was hypothesized that the fruit damage should be related to the amounts of flavonoids, and the decay rate after injury should be related to the color difference $b^{*}$ and total acids. As for the autumn fruits, the storability calculated by the decay index correlated significantly with fruit adhesiveness, indicating that fresh fruits with high adhesiveness had a relatively slower development rate of decay after injury.

\subsection{Partial least squares regression analysis}

The partial least squares regression analysis integrates the advantages of principal component analysis, canonical correlation

Table 2. Correlation between the storability and fruit quality of summer fruit.

\begin{tabular}{|c|c|c|c|c|c|c|c|c|c|c|c|c|c|c|c|c|c|}
\hline & Y1 & $\mathrm{Y} 2$ & $\mathrm{X} 1$ & $\mathrm{X} 2$ & $\mathrm{X} 3$ & $\mathrm{X} 4$ & $\mathrm{X} 5$ & X6 & $\mathrm{X} 7$ & $\mathrm{X} 8$ & X9 & $\mathrm{X} 10$ & $\mathrm{X} 11$ & $\mathrm{X} 12$ & $\mathrm{X} 13$ & $\mathrm{X} 14$ & $\mathrm{X} 15$ \\
\hline Y1 & 1 & 1 & & & & & & & & & & & & & & & \\
\hline $\mathrm{X} 1$ & 0.144 & 0.069 & 1 & & & & & & & & & & & & & & \\
\hline $\mathrm{X} 2$ & 0.092 & 0.206 & -0.04 & 1 & & & & & & & & & & & & & \\
\hline $\mathrm{X} 3$ & 0.101 & 0.052 & -0.017 & -0.146 & 1 & & & & & & & & & & & & \\
\hline $\mathrm{X} 4$ & 0.217 & 0.246 & -0.078 & 0.203 & 0.186 & 1 & & & & & & & & & & & \\
\hline X5 & 0.008 & 0.31 & -0.052 & 0.158 & -0.306 & 0.296 & 1 & & & & & & & & & & \\
\hline X6 & -0.185 & -0.182 & 0.236 & 0.172 & $-0.763^{* *}$ & 0.009 & 0.299 & 1 & & & & & & & & & \\
\hline $\mathrm{X} 7$ & -0.178 & -0.235 & -0.014 & 0.269 & $-0.824^{* *}$ & -0.053 & 0.173 & $0.920^{* *}$ & 1 & & & & & & & & \\
\hline X8 & -0.491 & $-0.644^{*}$ & -0.284 & -0.188 & 0.084 & 0.273 & 0.262 & 0.118 & 0.095 & 1 & & & & & & & \\
\hline X9 & 0.229 & 0.172 & 0.227 & -0.333 & 0.173 & 0.491 & $0.581^{\star}$ & 0.092 & -0.126 & 0.408 & 1 & & & & & & \\
\hline X10 & 0.115 & -0.008 & 0.074 & -0.096 & 0.176 & 0.301 & 0.468 & 0.107 & -0.053 & $0.655^{*}$ & $0.669^{*}$ & 1 & & & & & \\
\hline X11 & 0.167 & 0.164 & -0.122 & -0.021 & $0.718^{\star *}$ & 0.42 & 0.101 & -0.323 & -0.445 & 0.376 & 0.406 & $0.687^{* *}$ & 1 & & & & \\
\hline $\mathrm{X} 12$ & 0.171 & 0.096 & -0.093 & -0.07 & $0.630^{*}$ & 0.415 & 0.146 & -0.231 & -0.36 & 0.488 & 0.489 & $0.803^{* *}$ & $0.980^{* *}$ & 1 & & & \\
\hline $\mathrm{X} 13$ & -0.309 & $-0.560^{*}$ & -0.127 & 0.119 & 0.198 & 0.058 & -0.527 & -0.107 & 0.117 & 0.309 & -0.329 & -0.056 & 0.083 & 0.094 & 1 & & \\
\hline X14 & 0.037 & 0.174 & -0.05 & -0.117 & -0.265 & -0.449 & 0.294 & -0.065 & 0.009 & -0.133 & 0.067 & 0.082 & -0.252 & -0.221 & -0.194 & 1 & \\
\hline X15 & 0.224 & 0.124 & -0.212 & 0.077 & -0.498 & 0.482 & $0.628^{*}$ & 0.468 & 0.517 & 0.415 & 0.507 & 0.459 & -0.013 & 0.103 & -0.108 & 0.112 & 1 \\
\hline X16 & $0.579^{*}$ & 0.292 & -0.24 & -0.263 & 0.026 & 0.418 & -0.246 & -0.042 & 0.076 & -0.053 & 0.231 & 0.074 & 0.146 & 0.18 & 0.145 & -0.035 & 0.401 \\
\hline
\end{tabular}

${ }^{\star} \mathrm{P}<0.05 ;{ }^{* *} \mathrm{P}<0.01$. X1: 100-grain weight; X2: maximum single fruit weigh; X3: fruit hardness; X4: fruit handle-pulling strength; X5: soluble solids; X6: color difference L*; X7: color difference $\mathrm{a}^{*}$; X8: color difference $\mathrm{b}^{\star}$; X9: cohesiveness; X10: elasticity; X11: adhesiveness; X12: chewiness; X13: total acids; X14: vitamin C; X15: betaine; X16: flavonoids; Y1: decay rate; Y2: decay index. 
analysis and linear regression analysis, and it is applicable to the analysis of the 13 groups of data and 16 indicators used in this study. The partial least squares regression analysis was used to test the correlation between the fruit quality and storability in more detail and to verify the relationship between causality and the contribution of the variables.

\section{Storability calculated by the decay rates of summer fruits}

Figure 2 shows that the storability of summer fruits positively correlates with the contents of flavonoids and betaine and negatively correlates with color difference $b^{*}$ and total acids, which indicated that there were large regression coefficients for the flavonoids and color difference $b^{*}$.

The top eight weight coefficients ranked as flavonoids $>$ color difference $b^{*}>$ total acids $>$ cohesiveness $>$ fruit handle-pulling strength $>$ adhesiveness $>$ chewiness $>$ betaine.
Storability calculated by the decay index of the summer fruits

Figure 3 shows that the storability of summer fruits negatively correlates with the color difference $b^{*}$ and total acids and positively correlates with the flavonoids and soluble solids contents, with large regression coefficients for the total acids and color difference $b^{*}$

The top eight weight coefficients rank as color difference $\mathrm{b}^{*}>$ total acids $>$ soluble solids $>$ flavonoids $>$ fruit handlepulling strength $>$ color difference $\mathrm{a}^{*}>$ cohesiveness $>$ maximum single fruit weight.

Storability calculated by the decay rate of autumn fruits

Figure 4 shows the positive correlation between the storability and flavonoids and elasticity with larger regression coefficients.

Table 3. Correlation between the storability and fruit quality of autumn fruit.

\begin{tabular}{|c|c|c|c|c|c|c|c|c|c|c|c|c|c|c|c|c|c|}
\hline & Y3 & Y4 & $\mathrm{X} 1$ & $\mathrm{X} 2$ & $\mathrm{X} 3$ & $\mathrm{X} 4$ & $\mathrm{X} 5$ & X6 & $\mathrm{X} 7$ & $\mathrm{X} 8$ & X9 & X10 & $\mathrm{X} 11$ & $\mathrm{X} 12$ & X13 & X14 & $\mathrm{X} 15$ \\
\hline Y3 & 1 & 1 & & & & & & & & & & & & & & & \\
\hline $\mathrm{X} 1$ & -0.245 & -0.038 & 1 & & & & & & & & & & & & & & \\
\hline $\mathrm{X} 2$ & -0.29 & -0.293 & -0.04 & 1 & & & & & & & & & & & & & \\
\hline $\mathrm{X} 3$ & 0.145 & 0.287 & -0.017 & -0.146 & 1 & & & & & & & & & & & & \\
\hline $\mathrm{X} 4$ & 0.309 & 0.308 & -0.078 & 0.203 & 0.186 & 1 & & & & & & & & & & & \\
\hline $\mathrm{X} 5$ & 0.238 & 0.208 & -0.052 & 0.158 & -0.306 & 0.296 & 1 & & & & & & & & & & \\
\hline $\mathrm{X} 6$ & -0.169 & -0.305 & 0.236 & 0.172 & $-0.763^{* *}$ & 0.009 & 0.299 & 1 & & & & & & & & & \\
\hline $\mathrm{X} 7$ & -0.191 & -0.364 & -0.014 & 0.269 & $-0.824^{* *}$ & -0.053 & 0.173 & $0.920^{* *}$ & 1 & & & & & & & & \\
\hline X8 & 0.291 & 0.05 & -0.284 & -0.188 & 0.084 & 0.273 & 0.262 & 0.118 & 0.095 & 1 & & & & & & & \\
\hline X9 & 0.45 & 0.488 & 0.227 & -0.333 & 0.173 & 0.491 & $0.581^{\star}$ & 0.092 & -0.126 & 0.408 & 1 & & & & & & \\
\hline $\mathrm{X} 10$ & $0.674^{*}$ & $0.599^{*}$ & 0.074 & -0.096 & 0.176 & 0.301 & 0.468 & 0.107 & -0.053 & $0.655^{\star}$ & $0.669^{*}$ & 1 & & & & & \\
\hline $\mathrm{X} 11$ & 0.553 & $0.581^{\star}$ & -0.122 & -0.021 & $0.718^{\star *}$ & 0.42 & 0.101 & -0.323 & -0.445 & 0.376 & 0.406 & $0.687^{* *}$ & 1 & & & & \\
\hline $\mathrm{X} 12$ & $0.614^{\star}$ & $0.612^{*}$ & -0.093 & -0.07 & $0.630^{*}$ & 0.415 & 0.146 & -0.231 & -0.36 & 0.488 & 0.489 & $0.803^{\star *}$ & $0.980^{* *}$ & 1 & & & \\
\hline $\mathrm{X} 13$ & -0.147 & -0.172 & -0.127 & 0.119 & 0.198 & 0.058 & -0.527 & -0.107 & 0.117 & 0.309 & -0.329 & -0.056 & 0.083 & 0.094 & 1 & & \\
\hline X14 & 0.304 & 0.335 & -0.05 & -0.117 & -0.265 & -0.449 & 0.294 & -0.065 & 0.009 & -0.133 & 0.067 & 0.082 & -0.252 & -0.221 & -0.194 & 1 & \\
\hline X15 & 0.467 & 0.297 & -0.212 & 0.077 & -0.498 & 0.482 & $0.628^{*}$ & 0.468 & 0.517 & 0.415 & 0.507 & 0.459 & -0.013 & 0.103 & -0.108 & 0.112 & 1 \\
\hline $\mathrm{X} 16$ & $0.579^{*}$ & $0.555^{*}$ & -0.24 & -0.263 & 0.026 & 0.418 & -0.246 & -0.042 & 0.076 & -0.053 & 0.231 & 0.074 & 0.146 & 0.18 & 0.145 & -0.035 & 0.401 \\
\hline
\end{tabular}

${ }^{\star} \mathrm{P}<0.05 ;{ }^{*} \mathrm{P}<0.01$. $\mathrm{Y} 3$ : decay rate of autumn fruit; $\mathrm{Y} 4$ : decay index of autumn fruit.

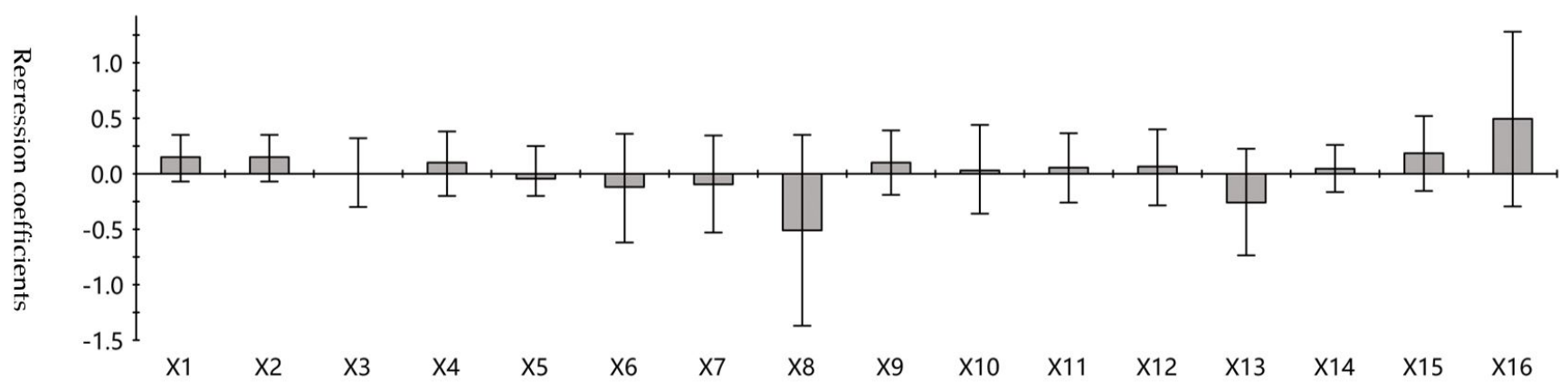

Quality indicators

Figure 2. Regression coefficients of the storability and fruit quality of fresh summer fruits (Evaluation of the decay rate). 


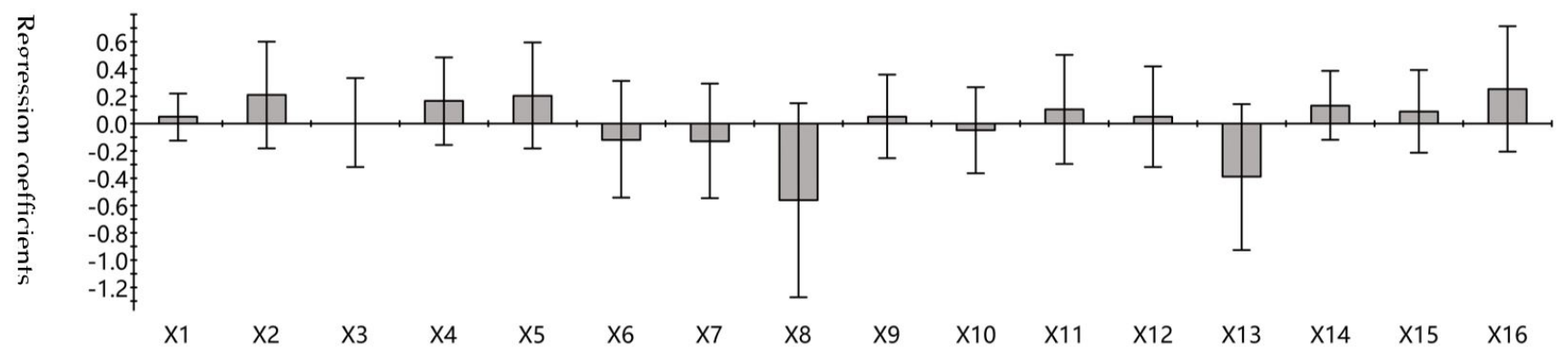

\section{Quality indicators}

Figure 3. Regression coefficients of the storability and fruit quality of fresh summer fruits (Evaluation of the decay index).

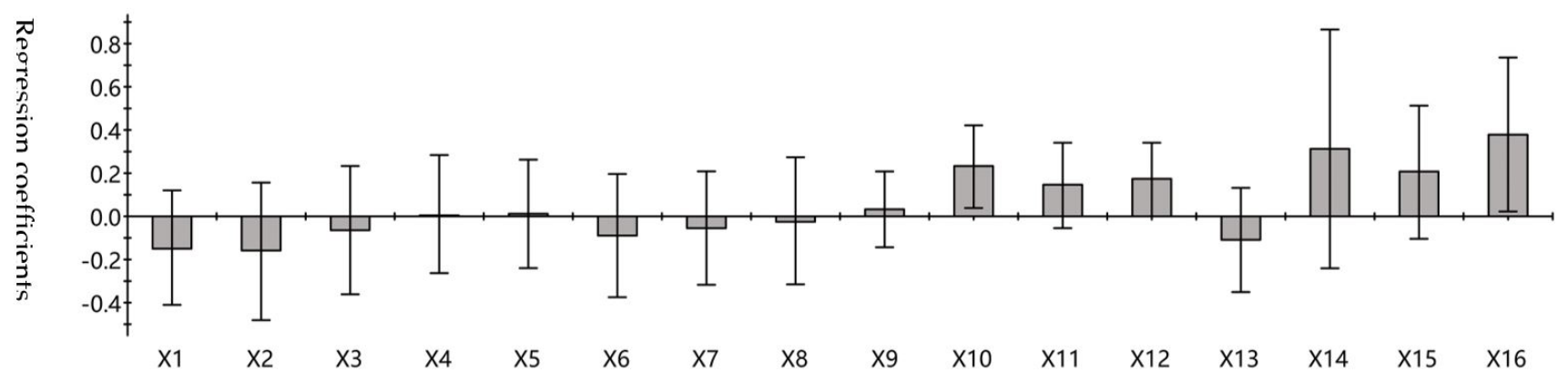

Quality indicators

Figure 4. Regression coefficients of storability and fruit quality of fresh autumn fruits (Evaluation of the decay rate).

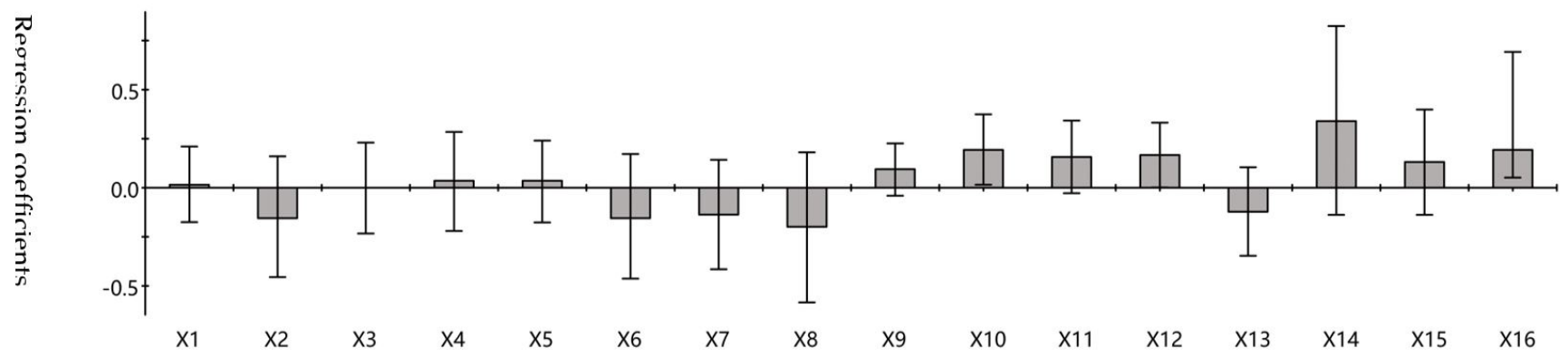

Quality indicators

Figure 5. Regression coefficients of storability and fruit quality of fresh autumn fruits (Evaluation of the decay index).

The top eight weight coefficients rank as flavonoids $>$ elasticity $>$ chewiness $>$ adhesiveness $>$ vitamin $\mathrm{C}>$ cohesiveness $>$ betaine $>$ color difference $b^{*}$.

Storability calculated by the decay index of autumn fruits

Figure 5 shows the positive correlation between storability and the contents of flavonoids and vitamin $\mathrm{C}$ with larger regression coefficients.
The top eight weight coefficients ranked as flavonoids $>$ chewiness $>$ vitamin $\mathrm{C}>$ elasticity $>$ adhesiveness $>$ cohesiveness $>$ color difference $b^{*}>$ fruit hardness.

It is worth noting that, in the simple correlation analysis, the content of vitamin $\mathrm{C}$ was positively correlated with storability but did not reach a significant level. In contrast, elasticity and adhesiveness correlated significantly positively with storability. Similarly, the histogram of the importance indices also showed 
the weight coefficients as vitamin C > elasticity $>$ adhesiveness, so there may be a higher correlation between vitamin $\mathrm{C}$ and storability calculated by the decay rate of autumn fruits, which will require further experimental verification.

\section{Discussion}

goji berries exhibits infinite inflorescence, with multiple blossoms and fruit periods in a year $(\mathrm{Hu}, 2014)$. The fruits are divided into summer fruits and autumn fruits according to the periods during which the fruits ripen. The fruits that ripen from mid-June to early July are called summer fruits; the fruits that ripen from mid to late September to early October are called autumn fruits. The appearance and nutrient composition in the fresh goji berries fruits vary at different harvesting periods (Yang, 2019). The results from this study indicate that for summer fruits, color difference $b^{*}$, total acids and soluble solids are more likely to affect the storability of the fresh fruits. However, for autumn fruits, physical properties, such as elasticity, chewiness and adhesiveness, more easily affect the storability of fresh fruits, which may be related to the different decay styles of autumn and summer fruits. Even if the storage temperature is the same, the summer and autumn fruits still exhibit different manners of decay. For example, the summer fruits can initially reveal mold spots and then whole fruit decay, while the autumn fruits initially soften and then sequentially shrink and mold. The reasons for these phenomena require further experiments for verification.

Regardless of whether the fruit ripened in the summer or autumn, there is a significant correlation between the content of flavonoids and the storability of the fresh fruits. Flavonoids are important active components of goji berries and can improve blood circulation and enhance immunity. In addition, they have anti-bacterial, anti-inflammatory, anti-oxidation and antiaging properties. These compounds have been used as natural pigments, antioxidants, and antibacterial agents in the food industry, medicine, cosmetics and other industries (Ali et al., 2019; Jarial et al., 2018). Berries contain much higher levels of flavonoids than fresh fruits. The lower content of flavonoids in the fresh goji berries may be one of the major reasons for the poor storability of the fresh fruits when compared with other berries (Bowen et al., 2018). They are not only water-soluble flavonoid glycosides but are also alcohol-soluble flavonoid aglycones, as well as comprising other compounds in the associated complex system (Yao et al., 2011). Currently, the main flavonoids isolated from goji berries are quercetin rhamnose dihexoside, quercetin3 -o-rutoside, luteolin, acacia-7,0- $\alpha$-1-rhamnosyl $(1,6)-\beta$-Dglucoside, 5,7,3'-trihydroxy-6,4', 5'trimethoxyflavone, among others. Different flavonoids may vary in their biological effects (Mocan et al., 2014, 2015). Currently, it is not known whether one or several flavonoids affect the ability of the goji berries fresh fruit to be stored for long periods. Therefore, the flavonoids should be analyzed in more detail to provide purified compounds for additional study.

Simultaneously, it has been reported that the content of flavonoids in the goji berries changed significantly during different development stages (Wang et al., 2013). The content of flavonoids in the unripe fruits is significantly higher than that in the mature fruits, so the content of flavonoids in different stages of the goji berries may reflect the maturity of fruits (Wang et al., 2013). Li et al. (2019) showed that flavonoid biosynthesis affected anthocyanin biosynthesis during fruit ripening. Therefore, further study could also explore the relationship between the flavonoid content and fruit maturity of different strains and explore the correlation between flavonoids and the ability of the fresh goji berries to maintain its quality during long-term storage.

According to the storability calculated by the decay rate and decay index, the positive and negative correlations between fruit quality and storability of fresh fruits are consistent. The storability calculated by the decay rate of the summer fruits is significantly negatively correlated with the color difference $b^{*}$ and total acids. The color difference $b^{\star}$ represents the yellowness value of fruits, that is, the large yellowness value and high total acid content can result in poor storability. The fruit epidermis functions to resist bacterial invasion (Ali et al., 2019). The decay rate of the fruit increases once the bacteria invade. A negative correlation with the storability calculated from the decay index indicates that a high total acid content will accelerate the decay rate of the fresh fruits after the peel is damaged. A positive correlation with the storability calculated from the decay rate indicates that content high in flavonoids will help to resist bacterial invasion from the peel.

\section{Conclusions}

The storability of different varieties of fresh fruits varies greatly, and the fruit quality also has different effects on storability. The storability of summer goji berries is more closely related to the intrinsic quality of the fresh fruits, and the storability of the autumn goji berries is more significant than the physical properties of fresh fruits. Through simple correlation analysis and partial least squares correlation analysis, it has been concluded that the storability calculated by the decay rate is significantly positively correlated with the content of the flavonoids in the summer goji berries. The storability calculated by the decay index is significantly negatively correlated with the color difference $b^{*}$ and total acids in summer goji berries. Similarly, the storability calculated by the decay rate is significantly positively correlated with the content of flavonoids, chewiness and elasticity of autumn goji berries. The storability calculated by the decay index is significantly positively correlated with the content of flavonoids and the chewiness of autumn goji berries.

The storability is explained by fruit quality, which is suitable for selecting varieties of edible goji berries, and is beneficial to the market development of these fruits, thereby increasing the marketization for this new kind of "super fruit".

\section{References}

Ali, M. C., Chen, J., Zhang, H., Li, Z., Zhao, L., \& Qiu, H. (2019). Effective extraction of flavonoids from Lycium barbarum L. fruits by deep eutectic solvents-based ultrasound-assisted extraction. Talanta, 203, 16-22. http://dx.doi.org/10.1016/j.talanta.2019.05.012. PMid:31202321.

Ban, Z., Wei, W., Yang, X., Feng, J., Guan, J., \& Li, L. (2015). Combination of heat treatment and chitosan coating to improve postharvest quality of wolfberry (Lycium barbarum). International Journal of Food Science \& Technology, 50(4), 1019-1025. http://dx.doi.org/10.1111/ijfs.12734. 
Barberis, A., Cefola, M., Pace, B., Azara, E., Spissu, Y., Serra, P. A., Logrieco, A. F., D’hallewin, G., \& Fadda, A. (2019). Postharvest application of oxalic acid to preserve overall appearance and nutritional quality of fresh-cut green and purple asparagus during cold storage: a combined electrochemical and mass-spectrometry analysis approach. Postharvest Biology and Technology, 148, 158-167. http://dx.doi.org/10.1016/j.postharvbio.2018.10.016.

Bowen, J., Billing, D., Connolly, P., Smith, W., Cooney, J., \& Burdon, J. (2018). Maturity, storage and ripening effects on anti-fungal compounds in the skin of 'Hass' avocado fruit. Postharvest Biology and Technology, 146, 43-50. http://dx.doi.org/10.1016/j.postharvbio.2018.08.005.

Bulens, I., Van de Poel, B., Hertog, M. L. A. T. M., De Proft, M. P., Geeraerd, A. H., \& Nicolai, B. M. (2012). Influence of harvest time and 1-MCP application on postharvest ripening and ethylene biosynthesis of 'Jonagold' apple. Postharvest Biology and Technology, 72, 11-19. http://dx.doi.org/10.1016/j.postharvbio.2012.05.002.

Cefola, M., Damascelli, A., Lippolis, V., Cervellieri, S., Linsalata, V., Logrieco, A. F., \& Pace, B. (2018). Relationships among volatile metabolites, quality and sensory parameters of 'Italia' table grapes assessed during cold storage in low or high $\mathrm{CO}_{2}$ modified atmospheres. Postharvest Biology and Technology, 142, 124-134. http://dx.doi. org/10.1016/j.postharvbio.2017.09.002.

Chan, H. C., Chang, R. C., Koon-Ching Ip, A., Chiu, K., Yuen, W. H., Zee, S. Y., \& So, K. F. (2007). Neuroprotective effects of Lycium barbarum Lynn on protecting retinal ganglion cells in an ocular hypertension model of glaucoma. Experimental Neurology, 203(1), 269-273. http:// dx.doi.org/10.1016/j.expneurol.2006.05.031. PMid:17045262.

Chen, Z., Kwong Huat Tan, B., \& Chan, S. H. (2008). Activation of T lymphocytes by polysaccharide-protein complex from Lycium barbarum L. International Immunopharmacology, 8(12), 1663-1671. http://dx.doi.org/10.1016/j.intimp.2008.07.019. PMid:18755300.

Costa, E. A., Sousa, P. H. M., Siqueira, A. C. P., Figueiredo, E. A. T., Gouveia, S. T., Figueiredo, R. W., Maia, C. S. C., \& Gomes, D. S. (2019). Fruit pastes with organic honey texturized with gellan gum: bioacessibility of antioxidant activity and sensory analysis fruit pastes with gellan and organic honey. Food Science and Technology, 39(3), 667-676. http://dx.doi.org/10.1590/fst.05518.

Gancarz, M. (2018). At harvest prediction of the susceptibility of potato varieties to blackspot after impact over long-term storage. Postharvest Biology and Technology, 142, 93-98. http://dx.doi.org/10.1016/j. postharvbio.2018.01.009.

Hayama, H., Tatsuki, M., Ito, A., \& Kashimura, Y. (2006). Ethylene and fruit softening in the stony hard mutation in peach. Postharvest Biology and Technology, 41(1), 16-21. http://dx.doi.org/10.1016/j. postharvbio.2006.03.006.

$\mathrm{Hu}, \mathrm{Z}$. (2014). The relationship between the structure, development and medicinal components of medicinal plants. Shanghai: Shanghai Science and Technology Press.

Huang, Y., Lu, R., Hu, D., \& Chen, K. (2018). Quality assessment of tomato fruit by optical absorption and scattering properties. Postharvest Biology and Technology, 143, 78-85. http://dx.doi.org/10.1016/j. postharvbio.2018.04.016.

Jarial, R., Thakur, S., Sakinah, M., Zularisam, A. W., Sharad, A., Kanwar, S. S., \& Singh, L. (2018). Potent anticancer, antioxidant and antibacterial activities of isolated flavonoids from Asplenium nidus. Journal of King Saud University - Science, 30(2), 185-192. http://dx.doi.org/10.1016/j.jksus.2016.11.006.

Jasmi, N., Mansor, N., Lim, E.-J., Yusof, N. L., Hajar-Azhari, S., \& Rahim, M. H. A. (2020). The effect of sonication and heat treatment on the physicochemical, nutritional and microbiological properties of different sugarcane variants. Food Science and Technology, 40(3), 551-556. http://dx.doi.org/10.1590/fst.12619.

Jatoi, M. A., Fruk, M., Buhin, J., Vinceković, M., Vuković, M., \& Jemrić, T. (2018). Effect of different storage temperatures on storage life, physico-chemical and sensory attributes of goji berry (Lycium barbarum L.) fruits. Erwerbs-Obstbau, 60(2), 119-126. http://dx.doi. org/10.1007/s10341-017-0344-8.

Jatoi, M. A., Jurić, S., Vidrih, R., Vinceković, M., Vuković, M., \& Jemrić, T. (2017). The effects of postharvest application of lecithin to improve storage potential and quality of fresh goji (Lycium barbarum L.) berries. Food Chemistry, 230, 241-249. http://dx.doi.org/10.1016/j. foodchem.2017.03.039. PMid:28407907.

Jin, M., Huang, Q., Zhao, K., \& Shang, P. (2013). Biological activities and potential health benefit effects of polysaccharides isolated from Lycium barbarum L. International Journal of Biological Macromolecules, 54, 16-23. http://dx.doi.org/10.1016/j.ijbiomac.2012.11.023. PMid:23200976.

Kafkaletou, M., Christopoulos, M. V., \& Tsantili, E. (2017). Short-term treatments with high $\mathrm{CO}_{2}$ and low $\mathrm{O}_{2}$ concentrations on quality of fresh goji berries (Lycium barbarum L.) during cold storage. Journal of the Science of Food and Agriculture, 97(15), 5194-5201. http:// dx.doi.org/10.1002/jsfa.8401. PMid:28447344.

Kiprovski, B., Borković, B., Malenčić, Đ., Veberič, R., Štampar, F., \& Mikulič-Petkovšek, M. (2018). Postharvest changes in primary and secondary metabolites of sweet cherry cultivars induced by Monilinia laxa. Postharvest Biology and Technology, 144, 46-54. http://dx.doi. org/10.1016/j.postharvbio.2018.05.012.

Li, G., Zhao, J., Qin, B., Yin, Y., An, W., Mu, Z., \& Cao, Y. (2019). ABA mediates development-dependent anthocyanin biosynthesis and fruit coloration in Lycium plants. BMC Plant Biology, 19(1), 317. http://dx.doi.org/10.1186/s12870-019-1931-7. PMid:31307384.

Li, T., Wu, Q., Zhou, Y., Yun, Z., Duan, X., \& Jiang, Y. (2018). 1 -Cysteine hydrochloride delays senescence of harvested longan fruit in relation to modification of redox status. Postharvest Biology and Technology, 143, 35-42. http://dx.doi.org/10.1016/j.postharvbio.2018.04.011.

Li, X. M., Ma, Y. L., \& Liu, X. J. (2007). Effect of the Lycium barbarum polysaccharides on age-related oxidative stress in aged mice. Journal of Ethnopharmacology, 111(3), 504-511. http://dx.doi.org/10.1016/j. jep.2006.12.024. PMid:17224253.

Manochai, B., Ingkasupart, P., Lee, S.-H., \& Hong, J.-H. (2018). Evaluation of antioxidant activities, total phenolic content (tpc), and total catechin content (tcc) of 10 sugar apple (Annona squamosa L.) cultivar peels grown in thailand. Food Science and Technology, 38(Suppl. 1), 294-300. http://dx.doi.org/10.1590/fst.22117.

Mocan, A., Vlase, L., Raita, O., Hanganu, D., Păltinean, R., Dezsi, S., Gheldiu, A.-M., Oprean, R., \& Crişan, G. (2015). Comparative studies on antioxidant activity and polyphenolic content of Lycium barbarum L. and Lycium chinense Mill, leaves. Pakistan Journal of Pharmaceutical Sciences, 28(Suppl. 4), 1511-1515.

Mocan, A., Vlase, L., Vodnar, D., Bischin, C., Hanganu, D., Gheldiu, A.-M., Oprean, R., Silaghi-Dumitrescu, R., \& Crișan, G. (2014). Polyphenolic content, antioxidant and antimicrobial activities of Lycium barbarum L. and Lycium chinense Mill. leaves. Molecules, 19(7), 10056-10073. http://dx.doi.org/10.3390/molecules190710056. PMid:25014533.

Muatasim, R., Ma, H., \& Yang, X. (2018). Effect of multimode ultrasound assisted extraction on the yield of crude polysaccharides from lycium barbarum (goji). Food Science and Technology, 38(Suppl. 1), 160-166. http://dx.doi.org/10.1590/1678-457x.14417.

Obianom, C., Romanazzi, G., \& Sivakumar, D. (2019). Effects of chitosan treatment on avocado postharvest diseases and expression 
of phenylalanine ammonia-lyase, chitinase and lipoxygenase genes. Postharvest Biology and Technology, 147, 214-221. http://dx.doi. org/10.1016/j.postharvbio.2018.10.004.

Ozturk, A., Yildiz, K., Ozturk, B., Karakaya, O., Gun, S., Uzun, S., \& Gundogdu, M. (2019). Maintaining postharvest quality of medlar (Mespilus germanica) fruit using modified atmosphere packaging and methyl jasmonate. $L W T, 111,117-124$. http://dx.doi.org/10.1016/j. lwt.2019.05.033.

Potterat, O. (2010). Goji (Lycium barbarum and L. chinense): phytochemistry, pharmacology and safety in the perspective of traditional uses and recent popularity. Planta Medica, 76(1), 7-19. http://dx.doi.org/10.1055/s-0029-1186218. PMid:19844860.

Schiassi, M. C. E. V., Carvalho, C. S., Lago, A. M. T., Curi, P. N., Pio, R., Queiroz, F., Resende, J. V., \& Souza, V. (2020). Optimization for sensory and nutritional quality of a mixed berry fruit juice elaborated with coconut water. Food Science and Technology, 40(4), 985-992. http://dx.doi.org/10.1590/fst.28919.

Shi, Y., Wei, C., \& Chen, Z. (2016). Research progress in postharvest physiology and preservation technology of fresh fruit. Journal of Preservation and Processing, 16, 102-106.

Silva, J. S., Ortiz, D. W., Garcia, L. G. C., Asquieri, E. R., Becker, F. S., \& Damiani, C. (2020). Effect of drying on nutritional composition, antioxidant capacity and bioactive compounds of fruit sco-products. Food Science and Technology, 40(4), 810-816. http://dx.doi. org/10.1590/fst.21419.

Su, J., Nie, Y., Zhao, G., Cheng, D., Wang, R., Chen, J., Zhang, S., \& Shen, W. (2019). Endogenous hydrogen gas delays petal senescence and extends the vase life of lisianthus cut flowers. Postharvest Biology and Technology, 147, 148-155. http://dx.doi.org/10.1016/j. postharvbio.2018.09.018.
Wang, C. C., Chang, S. C., Inbaraj, B. S., \& Chen, B. H. (2010). Isolation of carotenoids, flavonoids and polysaccharides from Lycium barbarum L. and evaluation of antioxidant activity. Food Chemistry, 120(1), 184-192. http://dx.doi.org/10.1016/j.foodchem.2009.10.005.

Wang, Z., Ma, Q., Mu, J., \& Zhang, Z. (2013). Study on the content of flavonoids in the fruit development of Lycium barbarum in Ningxia. Northern Horticulture, 11, 152-155.

Yang, S. (2019). Department of compilation of the history of the history. Ningxia: Huanghe Publishing Media Group Sunshine Publishing House.

Yao, X., Peng, Y., Xu, L.-J., Li, L., Wu, Q.-L., \& Xiao, P.-G. (2011). Phytochemical and biological studies of lycium medicinal plants. Chemistry \& Biodiversity, 8(6), 976-1010. http://dx.doi.org/10.1002/ cbdv.201000018. PMid:21674776.

Zhang, D., Xu, X., Zhang, Z., Jiang, G., Feng, L., Duan, X., \& Jiang, Y. (2018). 6-Benzylaminopurine improves the quality of harvested litchi fruit. Postharvest Biology and Technology, 143, 137-142. http:// dx.doi.org/10.1016/j.postharvbio.2018.05.002.

Zhao, J., Li, H., Xi, W., An, W., Niu, L., Cao, Y., Wang, H., Wang, Y., \& Yin, Y. (2015). Changes in sugars and organic acids in wolfberry (Lycium barbarum L.) fruit during development and maturation. Food Chemistry, 173, 718-724. http://dx.doi.org/10.1016/j. foodchem.2014.10.082. PMid:25466081.

Zhou, L., Liao, W., Chen, X., Yue, H., Li, S., \& Ding, K. (2018). An arabinogalactan from fruits of Lycium barbarum $\mathrm{L}$. inhibits production and aggregation of A $\beta 42$. Carbohydrate Polymers, 195, 643-651. http://dx.doi.org/10.1016/j.carbpol.2018.05.022. PMid:29805023.

Zou, S., Zhang, X., Yao, W., Niu, Y., \& Gao, X. (2010). Structure characterization and hypoglycemic activity of a polysaccharide isolated from the fruit of Lycium barbarum L. Carbohydrate Polymers, 80(4), 1161-1167. http://dx.doi.org/10.1016/j.carbpol.2010.01.038. 